\title{
Camargo Guarnieri e o ano de 1928 - Fronteira Catalográfica
}

\section{Domênico Barbieri}

Recentemente tivemos em mãos um volume encadernado, em cuja capa havia os dizeres: Catálogo de Composições de Camargo Guarnieri - São Paulo. Compunha-se de 222 páginas não numeradas, de $32+23 \mathrm{~cm}$, estando impressas colunas encimadas pelos dizeres: "Ordem cronológica - Título da Obra-Gênero de composição - $1^{\text {a }}$ audição e executantes - Edição - Observações". Nas dezenove primeiras páginas encontravam-se registros que se iniciavam com "Cantiga Noturna", de 1928, e se interrompiam na "Sonata $\mathrm{n}^{\mathrm{O}} 2$, para violoncelo e piano, de 1955. Contavam-se 220 obras, registradas de próprio punho pelo compositor, na sua grande maioria à tinta e algumas a lápis.

Julgamos, entretanto, ser o mais importante, neste "catálogo", o que Camargo Guarnieri escreve na coluna "Observações", na primeira página:

"As obras que escrevi de 1920 a 1928 não representam para mim valor rigorosamente artístico e, por isso, deixo de mencionar neste catálogo. É justamente a partir de 1928 que reconheço em minha obra aquilo que um artista sustenta como expressão da sua personalidade. Tudo quanto escrevi de 1920 a 1928 não deve, em hipótese alguma e sob nenhum pretexto, ser impresso e publicado, devendo apenas servir para estudo crítico e comparativo". M. Camargo Guarnieri.

Do texto de Camargo Guarnieri concluímos que o compositor é consciente da importância de sua obra e fornece elementos para a sua análise, antevendo que a mesma virá a ser objeto de "estudos 
críticos e comparativos". Destaca-se que Guarnieri julga a sua obra com notável clareza, atribuindo-lhe valor estético e, ainda, determina fimmemente o que deve ser resneitado em relação à mesma.

O compositor disse-me não se recordar da época em que iniciou os registros deste catálogo, informando que esta deliberacão deveu-se a conselho de Mário de Andrade.

O exame, seja deste Catálogo Inédito, seja do catálogo de obras de Camargo Guarnieri editado em 1977 pelo Ministério das Relacões Fxteriores ${ }^{(3)}$, revela a presença de várias peças datadas de 1928. Este fato demonstra, cabalmente, que Guamieri, ao estabelecer aquele limite, não o fez de maneira absoluta, pois incluiu obras datadas de 1928 , não as colocando no grupo das "proibidas".

José Eduardo Martins, em depoimento verbal ${ }^{(4)}$, considera: "É possivel, inclusive, acreditar-se ser o ano de 1928 uma data delimitadora da fronteira de opção estética clamamente voltada ao nacional. Saliente-se que é de 1928 a edição do Ensaio sobre a Música Brasileira de Mário de Andrade, editado por I. Chiarato e Cia., São Paulo, e que tão fortemente influenciara compositores brasileiros na edificação de uma linguagem nitidamente nacionalista. Entenda-se ter sido Mário de Andrade o eixo paradigmático para Camargo Guarnieri a quem o compositor dos Ponteios reverenciaria durante toda a sua existência. Poder-se-ia pensar nesta data como um "horizonte histórico" a ser preservado por Guarnieri". Seria, pois, 1928 o limite inferior das obras destinadas à publicação e o superior daquelas que deveriam ser apenas arquivadas. 
Revista Música, São Paulo, v.4, n.1: 19-29 maio 1993

21

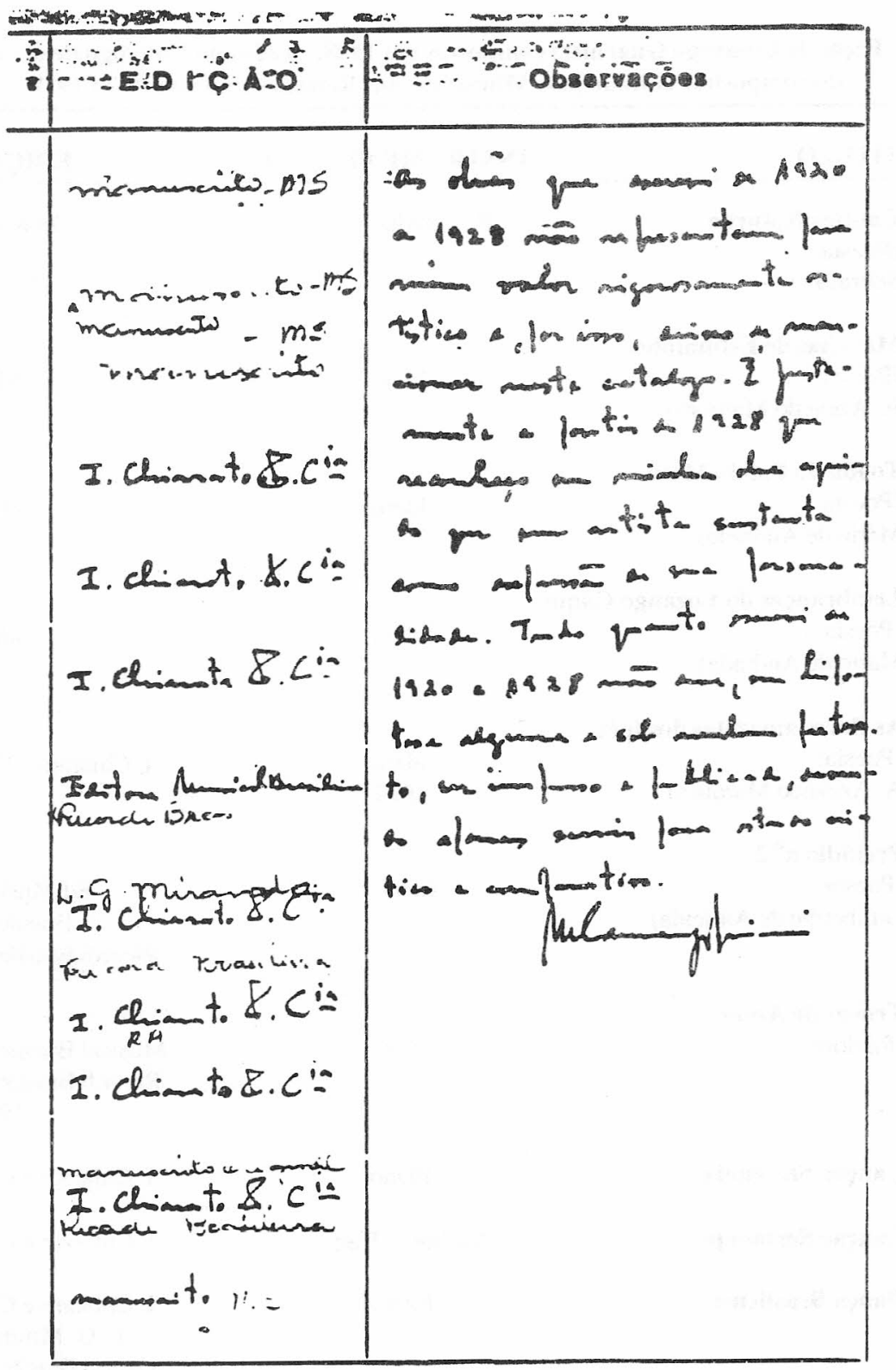




\section{QUADRO I}

Peças de Camargo Guarnieri compostas em 1928, citadas no Catálogo de obras do compositor editado pelo Ministério das Relações Exteriores em 1977:

Título

Cantiga Noturna

(Poesia:

Sobral Jr.)

Manchas de Esfuminho

(Pousia:

A. Azevedo Marques)

Toada do Pai do Mato

(Poesia:

Mário de Andrade)

Lembranças do Lozango Caqui

(Poesia

Mário de Andrade)

As flores amarelas dos ipês

(Poesia:

A. Azevedo Marques)

Prelúdio $n^{\circ} 2$

(Poesia:

Guilherme de Amleida)

Idem

Idem

1929

Idem

Trovas de Amor

(folclore)

Canção Sertaneja

Canção Sertaneja

Dança Brasileira

Idem

Idem

Idem

Piano

Piano
INSTRUMENTAÇÃO

EDIÇÃo

manuscrita

Idem

Idem

Idem

Ed.Musical

Brasileira

Ricordi Brasileira

I. Chiarato e Cia.

Musical Brasileira

Ricordi Brasileira

1963

I. Chiarato e Cia.

Violino e Piano

I. Chiarato e Cia.
I. Chiarato e Cia.

L. G. Miranda

Ricordi Brasileira Associated Music Publishers 
Sonatina $n^{\circ} 1$

(Molengamente - Ponteado

Piano

I. Chiarato e Cia.

e bem dengoso - Bem

Ricordi Brasileira

depressa)

Ricordi Argentina

Pesquisa realizada no acervo da recém-criada Fundação Camargo Guarnieri proporcionou-nos a catalogação das obras compostas entre 1920 e 1928 , que o compositor adverte "devem servir para estudo crítico e comparativo". (Quadro II).

\section{QUADRO II}

Obras de Camargo Guarnieri compostas entre 1920 e 1928, que o compositor proíbe publicação ou execução, servindo apenas para estudo. Abreviaturas: $\mathrm{De}=$ dedicatória $-\mathrm{Dt}=$ datada de $-\mathrm{s} / \mathrm{d}=$ sem data

\begin{tabular}{|c|c|c|c|}
\hline $\begin{array}{l}\text { Ano } \\
\text { Composição }\end{array}$ & Título & Instrumentação & Observações \\
\hline 1920 & Sonho de Artista & Piano & $\begin{array}{l}\text { Manuscrita } \\
\text { (Nota I) }\end{array}$ \\
\hline 1920 & Sonho de Artista & Piano & $\begin{array}{l}\text { Valsa lenta. Impressa. } \\
\text { Edição do Autor. Dd.: } \\
\text { Ao meu bom professor } \\
\text { Virginio Dias (Nota II) }\end{array}$ \\
\hline 1920 & Momentos tristes & Piano & $\begin{array}{l}\text { Valsa Dt: } 28-5-20 \\
\text { Dd: riscada }\end{array}$ \\
\hline 1922 & A mais bonita flor & Piano & $\begin{array}{l}\text { Valsa Dt: } 22-5-22 \text {. } \\
\text { Dd: A Sita. Laura Opys }\end{array}$ \\
\hline$?$ & Olhos que... falam & Piano & $\begin{array}{l}\text { Tango argentino. } \\
\text { Incompleto? }\end{array}$ \\
\hline 1922 & Noturno em Sol Maior & Piano & Dt: abril 22 \\
\hline 1922 & Ave Maria & sem especificação & Dt: abril 22 \\
\hline
\end{tabular}


Ano

\begin{tabular}{|c|c|c|c|}
\hline Composição & Título & Instrumentação & Observações \\
\hline 1922 & Septembre & Piano & Valsa. Dt: 8-7-22 \\
\hline 1922 & Septembre & Orquestrada & Valsa. Incompleta? \\
\hline 1922 & Pensando na partida & Piano & $\begin{array}{l}\text { Compasso } 3 / 4 . \\
\text { Dt:28-7-22 }\end{array}$ \\
\hline 1922 & Mazurka & Piano & \\
\hline 1923 & Primeiro estudo & Piano & Esboço. Dt: $12 / 16$ \\
\hline 1923 & Só & Piano & \\
\hline 1923 & Toada da minha terra & Piano & \\
\hline 1923 & Nunca mais & Canto-Piano & $\begin{array}{l}\text { Poesia F. Caldeira. } \\
\text { Incompleta? }\end{array}$ \\
\hline 1924 & Minueto & Piano & Op. $2 n^{\circ} 1 ;$ Dt:21/3/24 \\
\hline 1924 & Valsa lenta & Piano & $\begin{array}{l}\text { Op. } 2 \text { n²; Dt: } 2 / 4 / 24 \\
\text { Dd: Cecília de Santos }\end{array}$ \\
\hline $1924(?)$ & Canon & $\begin{array}{l}\text { Violino com } \\
\text { guia p/ flauta }\end{array}$ & Tema \\
\hline $1924(?)$ & Canto triste & Violino e piano & $\begin{array}{l}\text { Parte de violino com } \\
\text { guia p/ flauta. Cópia? }\end{array}$ \\
\hline 1924 & Valsa Lenta & Piano & Dt: $25 / 6 / 24$ \\
\hline 1924 & Sem nome & Sem especificação & Dt: $26 / 4 / 24$ \\
\hline 1924 & Deus e poesia & Canto-Piano & $\begin{array}{l}\text { Poesia: Antero de } \\
\text { Quental - Rascunho e } \\
\text { cópia }\end{array}$ \\
\hline 1924 & Dança Espanhola & Piano & Scherzino; Dt: $11 / 9 / 24$ \\
\hline 1924 & Rèverie & Violino-Piano & Dt: set. 24 \\
\hline 1924 & Sem nome & Violino-Piano & Dt: $28 / 8 / 24$ \\
\hline
\end{tabular}


Ano

Composição Título

1924

1924

1924

1924

1924

1925

1925

1925

1925

1925

1925

1925

1925

1925

1925

1925

1925
Lamentos

Valse Melancolique

Samba

Saudades

Sem nome

Canto triste $n^{\circ}-2$

Canto triste $n^{\circ} 1$

Rèverie

Noturno

A viola lá de casa

Tema e variações

Desalento

Berceuse

Tristeza

Nice

Tema para Rosinha

Saudade

\section{Instrumentação Observações}

Piano

Dt: set. 24

Piano

Dt: set. 24

Piano

Piano

Rascunho e cópia

Piano

Dt: $28 / 8 / 24$

(Fragmento?)

Violino e

Dt: $18 / 2 / 25$

Piano

Violino e

Dt: $1 / 9 / 25$

Piano

Violoncelo-

Dt: nov. 25

Piano

Canto-Piano

Poesia?

Piano

Incompleto?

Flauta-Piano Incompleto

Violino-Piano

Violino-Piano

Dt: $28 / 5 / 25$

Somente parte violino

Canto-Piano

Poesia: Alvarez

Azevedo - Dt: 8/5/25 -

2 cópias (Nota III)

Piano

Valsa lenta. Dt: $17 / 5 / 25$

Piano

Dt: $3 / 8 / 25$

Canto-Piano

Poesia: Carlos dos Santos - Dd: Andino Abreu - Dt: julho 25 


\begin{tabular}{|c|c|c|c|}
\hline $\begin{array}{l}\text { Ano } \\
\text { Composição }\end{array}$ & Título & Instrumentação & Observações \\
\hline 1925 & Plenilúnio & Canto-Piano & $\begin{array}{l}\text { Poesia: Maria Carolina } \\
\text { Dt: } 22 / 7 / 25\end{array}$ \\
\hline 1925 & Somno & Canto-Piano & $\begin{array}{l}\text { Poesia: Antero de } \\
\text { Quental - Dt: 8/9/25 }\end{array}$ \\
\hline 1925 & Ave Maria & Canto-Piano & Dt: $1 / 12 / 25$ (Nota IV) \\
\hline 1926 & Canon & Piano & $\begin{array}{l}\text { Dt: } 6 / 2 / 26 \\
\text { Original e cópia }\end{array}$ \\
\hline 1926 & Valsa Lenta & Piano & Esboço \\
\hline 1926 & Tema e Variaçōes & Piano & $\begin{array}{l}\text { Sete variações, a } \\
\text { oitava incompleta }\end{array}$ \\
\hline 1926 & O amolador & Piano & Incoinpleta \\
\hline 1926 & Berceuse & Piano & $\begin{array}{l}\text { Dt: } 10 / 3 / 26 . \\
\text { Duas cópias }\end{array}$ \\
\hline 1926 & Valsa & Piano & Op. $1 n^{2} 2$ \\
\hline 1926 & Sem nome & Piano & $\begin{array}{l}\text { Lento e Nostálgico } \\
\text { (incompleto) }\end{array}$ \\
\hline 1926 & Romance & Piano & \\
\hline 1926 & $\begin{array}{l}\text { Sonatina } \\
\text { (a la Mozart) }\end{array}$ & Piano & $\begin{array}{l}\text { Allegro moderato - } \\
\text { Minueto }\end{array}$ \\
\hline 1926 & Canção & Canto-Piano & $\begin{array}{l}\text { Poesia: Casemiro de } \\
\text { Abreu - Dt: } 12 / 6 / 26\end{array}$ \\
\hline 1926 & Tema e Variações & Piano & Incompleta \\
\hline 1927 & Canção & Canto-Piano & $\begin{array}{l}\text { Poesia: Casemiro de } \\
\text { Abreu - Dt: } 1 / 1 / 27 \\
\text { (Nota V) }\end{array}$ \\
\hline 1927 & Talvez & Canto-Piano & $\begin{array}{l}\text { Poesia: Lavínia A. } \\
\text { Viotti - Dt: } 2 / 8 / 27\end{array}$ \\
\hline
\end{tabular}


Ano

\begin{tabular}{llll} 
Composição & Título & Instrumentação & Observações \\
\hline 1927 & Meditação & Flauta-Violino & Dt: 4/12/27 \\
& & $\begin{array}{l}\text { Clarinete Sib } \\
\text { Quinteto de Cordas }\end{array}$ &
\end{tabular}

Violino-Piano

Dt: $25 / 10 / 27$

1927

Canção das Yaras

Canto-Piano

Poesia: Sobral Jr.

1927

Canção das Yaras

Canto-Quarteto de Cordas (Incompleta)

Poesia: Sobral Jr.

Violino-Piano

Prelúdio

Canto-Piano

Poesia: Guilherme de Alıneida (Esboço) (Nota VI)

Saudade

Canto-Piano

Poesia: Guilherme de Almeida - Dt: 23/11/27

1927

Noturno

Canto-Piano

Poesia: Guilherme de Almeida - Dt: 23/11/27

Duas Palavras

Piano

Cópia de Sylvio Bidoni

1927

Pluvial

Canto-Piano

Poesia: Eduardo

Guimarães

1927

Noturno

Piano

Dt: $6 / 1 / 27$. Original e cópia de S. Bidoni

1927

Fuga

Piano

Tema extraído da ópera Maria Petrowna de João Gomes de Araújo. Dt: $5 / 6 / 27$

Piano

Incompleta

1927-8

Caderno de exercícios de composição e provavelmente - de temas (Nota VII) 
Ano

\begin{tabular}{llll} 
Composição & Título & Instrumentação & Observações \\
\hline 1928 & Fuga a 3 vozes & $\begin{array}{l}\text { Soprano-Tenor- } \\
\text { Baixo }\end{array}$ & Tema próprio \\
1928 & Fuga a 2 vozes & Soprano-Baixo & Dt: 18/8/28 \\
s/d & Fuga a 2 vozes & Piano & $\begin{array}{l}\text { Tema de Bach } \\
\text { (incompleta) }\end{array}$ \\
s/d & Fuga a 2 vozes & Piano & Incompleta? \\
s/d & Fuga a 2 vozes & não definido & $\begin{array}{l}\text { Completa. Claves de } \\
\text { dó e de fá com } 4 \\
\text { sustenidos na armadura }\end{array}$ \\
s/d & Tristeza & Poral & Poesia? Incompleta \\
s/d & Fuga a 3 partes & Piano & Completa \\
s/d & Sem nome & Piano & \\
s/d & Fuga a 2 partes & Piano & Tema Mto. Baldi
\end{tabular}

O quadro I mostra nada menos de onze peças de Camargo Guarnieri, compostas em 1928, várias delas de grande importância artística, várias editadas e algumas, posteriormente, gravadas em discos.

Por sua vez, o Quadro II relaciona, neste ano de 1928, uma peça coral incompleta (Tristeza) e duas fugas datadas. No final da coleção há, sem menção de data, uma peça sem nome e cinco fugas. Considere-se que as fugas poderiam ter sido elaboradas com finalidade única de exercício.

Portanto, em 1928, quantitativa e qualitativamente, há mais e melhores peças destinadas à publicação do que aquelas "proibidas", salientando-se que cerca da metade das primeiras citadas alcançaram apreciável e persistente repercussão. 


\section{AGRADECIMENTOS}

O autor agradece: a colaboração prestada pela Fundação Camargo Guarnieri; o apoio inestimável da Sra. Vera Sílvia Camargo Guarnieri e as valiosas sugestões do pianista e musicólogo Prof. Dr. José Eduardo Martins.

\section{NOTAS}

1) Camargo GUARNIERI, Catálogo de Composições. Manuscrito, sem data, sem páginas numeradas. Acervo da Fundação Camargo Guarnieri.

2) Camargo GUARNIERI: Informação pessoal.

3) Camargo Guarnieri: Catálogo de Obras. Ministério das Relações Exteriores, 1977, sem páginas numeradas.

4) José Eduardo MARTINS: depoimento ao articulista.

(Nota I) Neste manuscrito de "Sonho de Artista" está registrado de próprio punho: "Primeira composição que escrevi" e a data "?-4-21". Ora, a valsa fora escrita em 1920, portanto, esta data de 1921 deve ser a do registro da observação.

(Nota II) A impressão da valsa "Sonho de Artista" foi custeada por amigos da família, segundo a infornação do compositor.

(Nota III) Contraponto elaborado; ao piano: mão esquerda três vozes, mão direita: duas vozes.

(Nota IV) Contraponto elaborado.

(Nota V) Existe uma "Canção" com poesia de Casemiro de Abreu, datada de $12 / 6 / 26$. Seria esta, de 1927 , uma nova versão?

(Nota VI) O tex to de "Prelúdio", de 1927, de Guilherme de Almeida, é o mesmo de "Prelúdio n ${ }^{\circ} 2^{\prime \prime}$ (como o poeta nomeia o seu poema). Entretanto, na versão musical de 1928 , o canto segue uma linha semelhante à da versão anterior, enquanto que a parte pianística é bastante diferente. A versão de 1927, escrita a lápis, seguramente foi descartada pelo compositor.

(Nota VII) O que denominamos "Caderno de exercícios de composição e de temas" deverá merecer, em futuro próximo, uma análise pormenorizada.

Domênico Barbieri é Médico e Professor Doutor do Departamento de Análises Clínicas e Toxicológicas da Faculdade de Ciências Farmacêuticas da Universidade de São Paulo. 